\title{
A universal karyotypic system for hexaploid and diploid Avena species brings oat cytogenetics into the genomics era
}

Wenxi Jiang ${ }^{1}$, Chengzhi Jiang ${ }^{1}$, Weiguang Yuan ${ }^{1}$, Meijun Zhang ${ }^{2}$, Zijie Fang ${ }^{1}$, Yang Li ${ }^{1}$, Guangrong Li', Juqing Jia ${ }^{2^{*}}$ and Zujun Yang ${ }^{1^{*}}$

\begin{abstract}
Background: The identification of chromosomes among Avena species have been studied by C-banding and in situ hybridization. However, the complicated results from several cytogenetic nomenclatures for identifying oat chromosomes are often contradictory. A universal karyotyping nomenclature system for precise chromosome identification and comparative evolutionary studies would be essential for genus Avena based on the recently released genome sequences of hexaploid and diploid Avena species.

Results: Tandem repetitive sequences were predicted and physically located on chromosomal regions of the released Avena sativa OT3098 genome assembly v1. Eight new oligonucleotide (oligo) probes for sequential fluorescence in situ hybridization (FISH) were designed and then applied for chromosome karyotyping on mitotic metaphase spreads of $A$. brevis, A. nuda, A. wiestii, A. ventricosa, A. fatua, and A. sativa species. We established a high-resolution standard karyotype of A. sativa based on the distinct FISH signals of multiple oligo probes. FISH painting with bulked oligos, based on wheat-barley collinear regions, was used to validate the linkage group assignment for individual A. sativa chromosomes. We integrated our new Oligo-FISH based karyotype system with earlier karyotype nomenclatures through sequential C-banding and FISH methods, then subsequently determined the precise breakage points of some chromosome translocations in A. sativa.
\end{abstract}

Conclusions: This new universal chromosome identification system will be a powerful tool for describing the genetic diversity, chromosomal rearrangements and evolutionary relationships among Avena species by comparative cytogenetic and genomic approaches.

Keywords: Avena, Oligo-probes, Chromosome identification, FISH

\section{Background}

The common oat (Avena sativa $\mathrm{L}$., $2 \mathrm{n}=6 \mathrm{x}=42$, AACC $\mathrm{DD}$ ) is a temperate crop (annual production of 23 million tons in 2017; http://faostat.fao.org) which is primarily used for livestock feed and partially for human food. It is also a food crop recommended by nutritionists because

\footnotetext{
*Correspondence: jiajuqing@126.com; yangzujun@uestc.edu.cn

${ }^{2}$ College of Agronomy, Shanxi Agricultural University, 030801 Taigu, China

${ }^{1}$ Center for Informational Biology, School of Life Science and Technology, University of Electronic Science and Technology of China, 611731 Chengdu, China
}

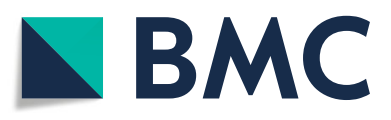

( The Author(s). 2021 Open Access This article is licensed under a Creative Commons Attribution 4.0 International License, which permits use, sharing, adaptation, distribution and reproduction in any medium or format, as long as you give appropriate credit to the original author(s) and the source, provide a link to the Creative Commons licence, and indicate if changes were made. The images or other third party material in this article are included in the article's Creative Commons licence, unless indicated otherwise in a credit line to the material. If material is not included in the article's Creative Commons licence and your intended use is not permitted by statutory regulation or exceeds the permitted use, you will need to obtain permission directly from the copyright holder. To view a copy of this licence, visit http://creativecommons.org/licenses/by/4.0/. The Creative Commons Public Domain Dedication waiver (http://creativecommons.org/publicdomain/zero/1.0/) applies to the data made available in this article, unless otherwise stated in a credit line to the data. its consumption helps reduce blood cholesterol levels and heart disease risk [1,2]. The genus Avena consists of several diploid, tetraploid and hexaploid species. All diploid species contain either the AA or CC genomes, the tetraploid species carry the AABB, AACC, CCCC or CCDD genomes, while the hexaploid species have AACCDD genomes [3]. The cultivated oat was domesticated from the wild and weedy $A$. sterilis $\mathrm{L}$., which arose from hybridization between a CCDD allotetraploid and an AsAs diploid $[4,5]$. 
Avena represents a remarkable model to study because of its history of polyploidy, lineage divergence and complex reticulate evolution [6-8]. The relationships and origins among Avena species have been intensively studied by molecular and cytological approaches $[8,9]$. The earliest investigations into genome structure involved meiotic chromosome pairing, C-banding and genomic in situ hybridization (GISH) which enabled the sub-genome chromosomes in common oat to be distinguished [6-13]. Identification of the chromosome complements of Avena species has been successfully achieved using fluorescence in situ hybridization (FISH) based on the satellite sequence pAs120a, specific to the A genome, in combination with rDNA probes and the sequence pAm1, satellite DNA specific to the C genome $[14,15]$. Several cytogenetic nomenclatures have been established for identifying all 21 hexaploid oat chromosomes and assigning these chromosomes to each of the three subgenomes [16-18]. However, the results from different researchers are often complicated and require specialized training to interpret and reproduce due to a lack of conserved FISH probes and frequent intergenomic rearrangements which have occurred in the different oat species [19, 20]. Establishment of a universal karyotyping nomenclature system for each individual oat chromosome pair would be of enormous benefit to Avena researchers.

FISH using probes from different families of satellite sequences can generate chromosome- and genome-specific patterns, and consequently allows for the identification of chromosome pairs at mitotic metaphases [21, 22]. The non-denaturing fluorescence in situ hybridization (NDFISH), using oligonucleotide (oligo) probes of repetitive sequences, has been confirmed as a simple, cheap and high-throughput method for painting the chromosomes of different plant species [23-26]. The FISH signal patterns of some probes, including simple sequence repeat (SSR) motifs, have previously been documented for several different oat lines [20, 27-31]. However, the FISH patterns of those SSRs are highly polymorphic, which may cause difficulties for the assignment of specific chromosomes to certain sub-genomes and linkage groups.

Genome research on oat has received less attention than for wheat (Triticum aestivum L.) and barley (Hordeum vulgare L.), possibly because it is not a relatively prominent component of the human diet [32-34]. Maughan et al. [35] reported two complete genome sequences of representative diploid Avena spp., A. atlantica (A genome) and $A$. eriantha ( $\mathrm{C}$ genome), and the first hexaploid oat OT3098 reference genome v1 has also been released recently (https://wheat.pw.usda.gov/GG3/node/922). These genome databases have enabled researchers to employ bioinformatic approaches to determine the genomic locations of tandem repeats (TR) along the oat chromosomes $[25,36,37]$ and develop FISH probes suitable for chromosome identification. Moreover, oligo-FISH painting systems using the bulked pools of 40-50 bp lengths, which are specific to an entire chromosome or a specific region, have successfully enabled the karyotyping of several sequenced plant species with various genome sizes [22, 37-39]. The oligo-FISH painting system was recently used to assign specific linkage groups to chromosomes in Triticeae species [37]. Therefore, this comparative oligoFISH painting system may also be modified to enable karyotyping of the oat chromosomes, since the divergence time between oats and members of the Triticeae tribe has been estimated to be only 25.5-26.5 MYA [40].

In the current study, we predict the chromosomal distribution of tandem repeats (TRs) by use of a web server analyzing data from recently released Avena genome sequences. The TR-oligo based ND-FISH and single copy oligo pool-based FISH painting methods have been integrated to establish a standard nomenclature system for identification of individual chromosomes of Avena species. Our study will fill the important gap in the cytogenetic and genomic approaches for precise identification of chromosome segments and rearrangements for future oat improvement.

\section{Results}

\section{Genomic distribution of TRs in A. sativa genomes}

In order to investigate the proportional contribution of the TRs in A. sativa genomes, the sequence data of all 21 individual chromosomes from the cultivated oat OT3098 reference assembly v1 were analyzed [25]. We obtained 10,832 arrays of TRs comprising a total length of $447.21 \mathrm{Mb}$, which constitutes $4.16 \%$ of the total 10.74 $\mathrm{Gb}$ assembled oat genome (Table S1). The lowest proportion of chromosome sequence length contributed by TRs was for chromosome 6D at $1.11 \%$, and highest proportion of sequence length contributed by TRs was for chromosome $6 \mathrm{C}$ reaching $8.67 \%$ (Figure S1a). The distribution of TRs across the seven different linkage groups was also compared, and a clear variation was observed (Figure S1b). The coverage of TR content varied across the A, C and D genomes. For both the overall length and the percentage of TRs of the chromosomes for the $\mathrm{C}$ genome were much higher than for the $\mathrm{A}$ and $\mathrm{D}$ genomes. The average TR content among the A, C and D genomes was $2.59 \%, 6.92$ and $2.17 \%$, respectively (Figure S1c).

\section{Physical locations of known TRs and validation by ND- FISH}

FISH probes, usually several hundred base pairs in length, have been previously used for identification of mitotic metaphase chromosomes of Avena species [4144 ]. A conserved repetitive DNA element was located in the centromeres of cereal chromosomes, and 
subsequently was also localized to centromeric regions of oat chromosomes $[45,46]$. The predicted copy number of the cereal centromeric sequence (CCS1) for $A$. sativa was estimated by the D2DSC web server [25], and the distribution on oat chromosome regions is shown in Table S2. We found that this CCS1 repeat was distributed mainly on the centromeric regions of chromosomes of the $\mathrm{A}$ and $\mathrm{D}$ genomes (Fig. 1a-c). ND-FISH using probe Oligo-CCS1 showed clear centromeric signals on 28 chromosomes, which are presumably the oat A and $\mathrm{D}$ genomes, but lacked any hybridization on the $\mathrm{C}$ genome of BaiyanII (Fig. 1d). This result is consistent with the FISH study of Tomas et al. [19]. We thus propose that the predicted locations of Oligo-CCS1 sites match with the cytological positions of the centromeres, suggesting the precision and validity of the sequence assembly for A. sativa.

The relative positions of the 5 and $18 \mathrm{~S}$ rDNA loci is a highly conserved characteristic of cereal and oat genomes $[47,48]$. The distribution of 12 major $5 \mathrm{~S}$ rDNA signal sites, located on four oat chromosome pair, was revealed by ND-FISH probed by Oligo-5SrDNA (Fig. 2). The predicted physical locations of $5 \mathrm{SrDNA}$, based on the oat reference genome $\mathrm{v} 1$, are shown on the assembled oat chromosomes 4 A, 4D, 3C and 7 C (Fig. 2c), and these sites are consistent with the FISH results. Similarly, studies were also conducted on the predicted physical locations and subsequent FISH verification of $18 \mathrm{SrDNA}$ on oat chromosomes $4 \mathrm{~A}$ and 3D (Fig. 2a and c).
Linares et al. [49] isolated a 670-bp satellite DNA sequence, As120a, (NCBI genbank number: AJ001922) specific to the A-genome chromosomes in A. sativa. An oligo probe Oligo-pAs120a was designed based on the As120a sequences (Table 1). The physical distributions and copy number estimation of Oligo-pAs120a, predicted by B2DSC for the A. sativa genome assembly v1, are shown in Fig. 3. The results showed that As120a displays about 1,800 to 2,300 copies for each A-genome chromosome, while the $\mathrm{C}$ and $\mathrm{D}$ genomes have fewer than 600 copies per chromosome. FISH with probe Oligo-pAs120a on cultivated oat mitotic spreads revealed that 14 chromosomes showed clear hybridization, and thus we conclude that these are the A-subgenome chromosomes (Fig. 3e).

Solano et al. [50] reported a satellite DNA sequence, pAm1, specific to the oat $\mathrm{C}$ genome, containing an insert of 464 bp (NCBI genbank number: X83958.1) isolated from $A$. murphyi. Based on the tandem repeats prediction in the A. sativa genome v1 by the B2DSC web server, we found that pAm1 repeats contained a core consensus $51 \mathrm{bp}$ monomer sequence with a copy number of around 260,000-380,000 among the Cgenome chromosomes (Fig. $3 \mathrm{~b}$ ). A probe named Oligo6C51 (Table 1), representing pAm1 for ND-FISH, was hybridized to the metaphase cells of $A$. sativa and $A$. fatua. As shown in Fig. 3d and e, the probe Oligo-6C51 had extremely strong hybridization signal sites located across the entire $14 \mathrm{C}$ genome chromosomes of oat

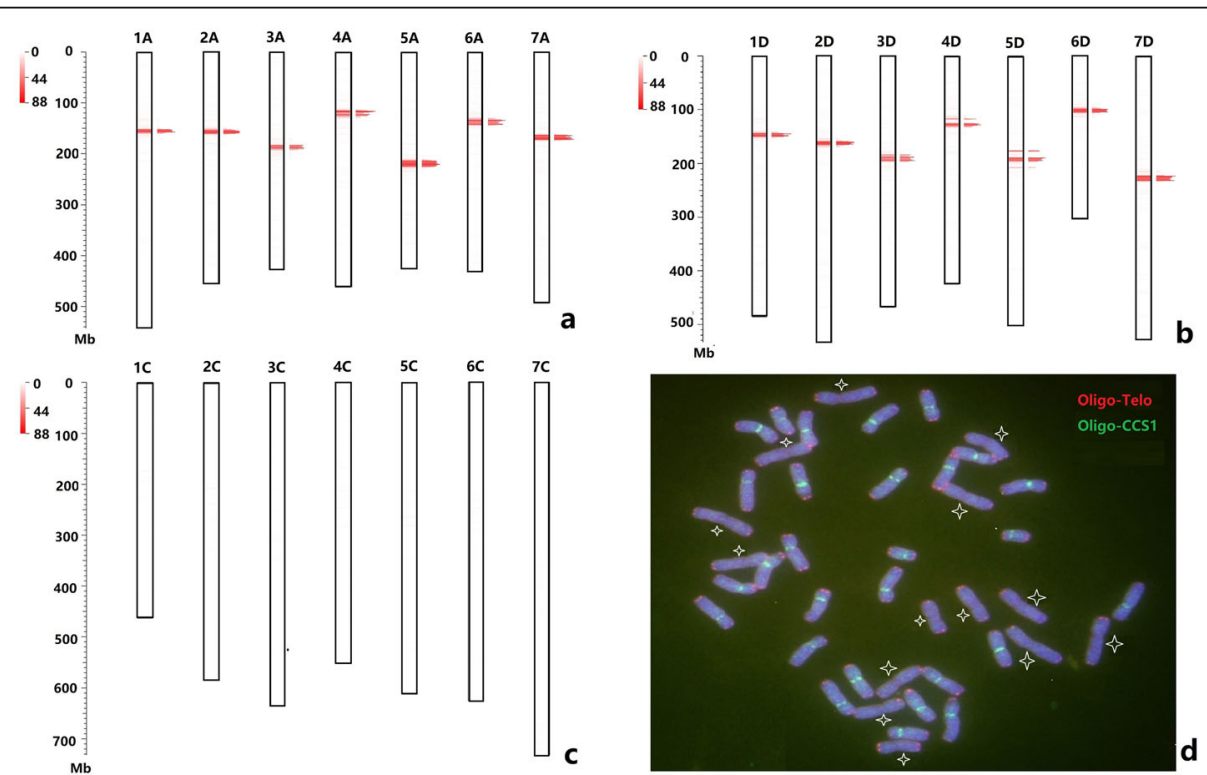

Fig. 1 The physical distribution (a-c) and ND-FISH results (d) of Oligo-CCS1 in chromosomes of oat. a-c The prediction of Oligo-CCS1 in oat OT3098 reference assembly v1 was according to website B2DSC by using default parameters for the blast and filter steps. The parameters pident $=85$, qcovhsp $=80$. Red bars: the positions of Oligo-CCS1. $\mathbf{d}$ ND-FISH for mitotic metaphase of Baiyanll showing the hybridization of OligoCCS1 (green) + Oligo-Telo (red) on 28 chromosomes, with the 14 chromosomes of C-genome devoid of centromeric hybridization signals (star marked) 

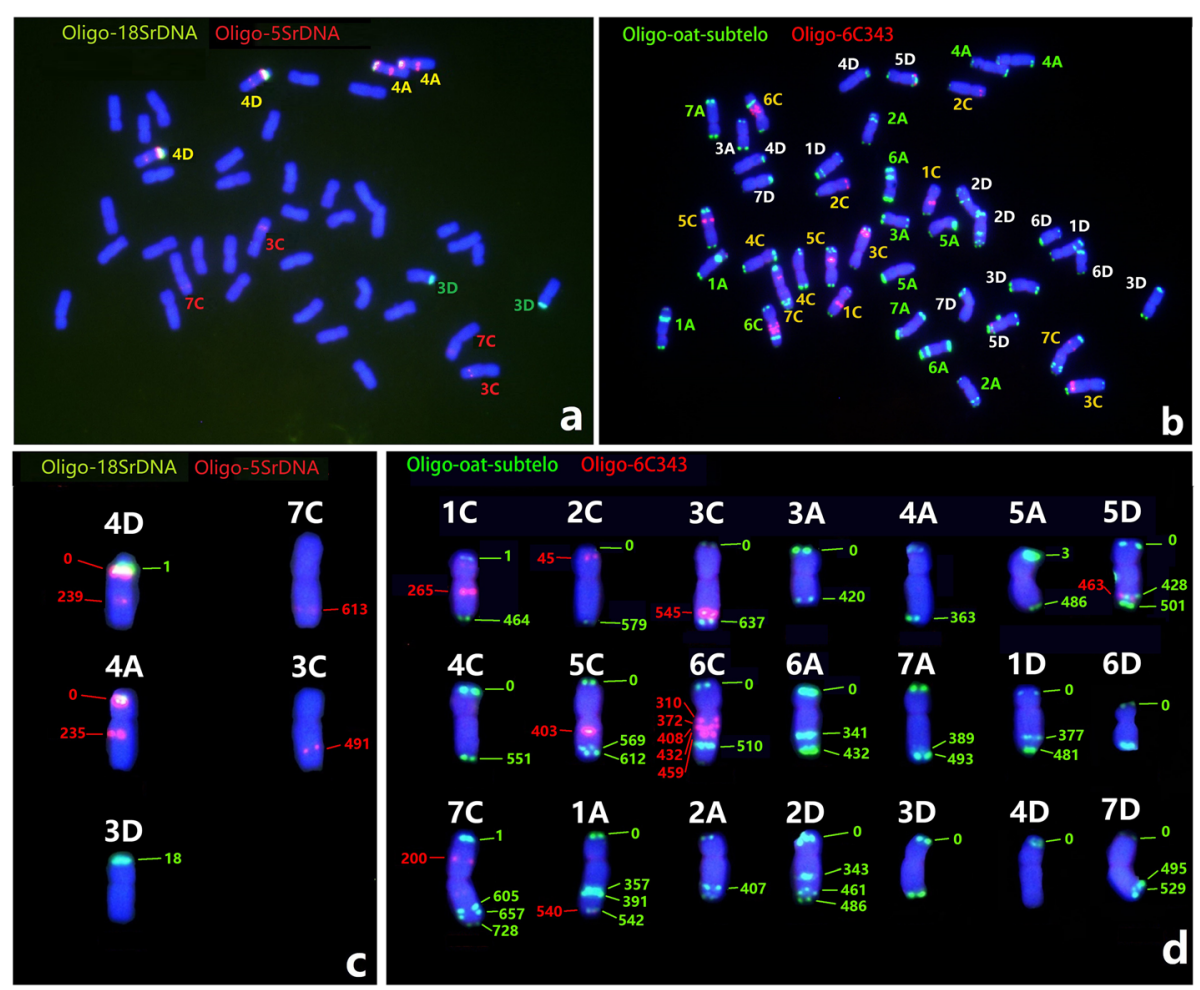

Fig. 2 The ND-FISH of oligo probes Oligo-5SrDNA + Oligo-18SrDNA (a) and Oligo-oat-subtelo + Oligo-6C343 (b), and their hybridization sites (c, d) on metaphase chromosomes of Avena sativa cv. Baiyanll The numbers (in Mb) show the central physical positions predicted on the A. sativa reference genome assembly v1 using the B2DSC web server

Table 1 The sequences of TRs oligo probes for Avena chromosome identification by ND-FISH

\begin{tabular}{|c|c|c|}
\hline Oligo probes & Sequences & Reference \\
\hline Oligo-CCS1 & CCGTTGATAGAGGCAAAGGTGTCCCGTCTITGATGAGA & [23] \\
\hline Oligo-oat-subtelo & CAAACATGTATCGGGTCTTACGGTCATTTTAAATCGCCCT & This study \\
\hline Oligo-6C51 & AACACACATGCAATGACTCTAGTGGTTGATCCATGTGTGGTTTGTGGAAAG & This study \\
\hline Oligo-6C343 & AGGACATATGTACATGGAGAGCCAAGGTTGGGCCAACTTTGCCACATTCT & This study \\
\hline Oligo-8C355 & ACTTCTTCTGACAGGGGTAGCCCGGTGTAGCCCTCACTTGTTTA & This study \\
\hline Oligo-4C709 & ATGTGATGATGTAAAACCATGTTTGGGAACATGTTGTGACAAGATCTAC & This study \\
\hline Oligo-3A352 & GTGCTTGCATGTGTCCCCCCTCGCATGCATGCGCTCTAACCTAGAGGCGAA & This study \\
\hline Oligo-6C686 & GAGCCAAGGTTGGGCCAACTTTGCCACATTCTAGGCCCCGGTTGTGACGCGGCGG & This study \\
\hline Oligo-4A70 & AACACTTTCAAATTAAAAAAATTATACAACTCTTAATGTAAAAGAGTGT & This study \\
\hline Oligo-pAs120a & GGTTIATCTCATACTATCTGTACCTGATTAGTAATTGTTGTAACTACAACGGAATGGTTAACT & [49] \\
\hline Oligo-18SrDNA & GGGCAAGTCTGGTGCCAGCAGCCGCGGT & [25] \\
\hline Oligo-5SrDNA & GTACTACTCTCGCCCAAGCACGCTTAACTTCGGAGTTCTGA & [25] \\
\hline Oligo-HvCSR & ACAACGACAACAACGACAATGACGAGA & [25] \\
\hline Oligo-Telo & TTAGGGTTAGGGTTAGGG & [24] \\
\hline Oligo-(CAA) $)_{7}$ & CAACAACAACAACAACAACAA & [24] \\
\hline Oligo-(GAA) & GAAGAAGAAGAAGAAGAAGAA & [24] \\
\hline Oligo-(TAG) 7 & TAGTAGTAGTAGTAGTAGTAG & [24] \\
\hline Oligo-(ACT) 6 & ACTACTACTACTACTACT & [24] \\
\hline Oligo-(GT) 10 & GTGTGTGTGTGTGTGTGTGT & {$[24]$} \\
\hline
\end{tabular}



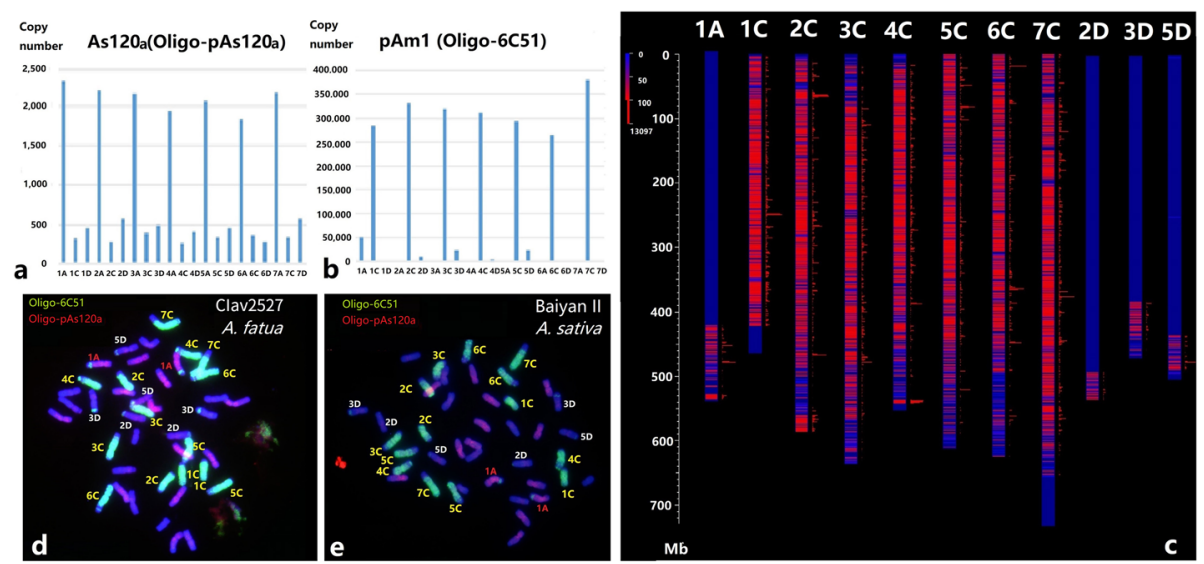

Fig. 3 Copy number prediction and FISH validation of Oligo-pAs120a and Oligo-6C51 on hexaploid oat chromosomes. The copy number prediction of As120a (a) and PAm1 (b) was shown on A. sativa genome assembly v1, and a visualized distribution of pAm1 (Oligo-6C51) was indicated (c) by B2DSC web server. The probes Oligo-pAs120a + Oligo-6C51 (d, e) were used for FISH of lines Clav2527 (A. fatua) and Baiyanll (A. sativa), respectively

cultivar BaiyanII and A. fatua Clav2527. Faint signals also appeared on the telomeric regions of four chromosome pairs (Fig. 3d, e), which are consistent to the predicted chromosomes $1 \mathrm{~A}, 2 \mathrm{D}, 3 \mathrm{D}$, and 5D (Fig. 3c). Therefore, the ND-FISH hybridization patterns of probes Oligo-6C51 for the $\mathrm{C}$ genome and OligopAs120a for the A genome will facilitate sub-genome assignment of individual chromosomes in the hexaploid oat, with the remaining D-genome chromosomes showing limited hybridization by these two probes.

\section{Production of new repetitive probes for chromosome identification}

In order to establish the standard karyotype of hexaploid oat, we need to produce more probes with each of their physical positions clearly defined for precise chromosomal painting. In this present study, a total of eight novel oligo probes were designed from the predicted TR database (Table 1), then their physical distributions and estimation of copy numbers were obtained using the B2DSC web server. These oligos appeared as distinct and stable hybridization signals on the chromosomes of BaiyanII by ND-FISH. As shown in Fig. 2, the probe Oligo-oat-subtelo produced hybridization signals on telomeric or sub-telomeric regions of one or both arms of almost all chromosomes, while Oligo-6C 343 produced hybridization signals on chromosomes $1 \mathrm{C}, 2 \mathrm{C}, 3 \mathrm{C}$, 5 C, 6 and 7 C (Fig. 2). The oligo-probe Oligo-4A70 had hybridization sites only on the distal region of the short arm of chromosome $4 \mathrm{~A}$. Therefore, in combination with $\mathrm{A}$ and $\mathrm{C}$ - genome specific probes, the oat chromosomes were also recognizable by using a cocktail of the probes Oligo-oat-subtelo, Oligo-6C343 and Oligo-8C355 (Figs. 3 and 4). The hybridization patterns of above mentioned probes for individual oat chromosomes, and their physical locations with units of $\mathrm{Mb}$ in the A. sativa genome, will be able to distinguish all oat chromosomes with different origins (Figs. 2, 3 and 4). As expected, some probes were successfully hybridized to chromosomes by ND-FISH, but their copy number by TR prediction was largely under-estimated, which possibly implies that the sequence assembly v1 of the related region needs to be improved.

\section{Chromosome nomenclature system comparison}

Jellen et al. [10] reported a karyotyping system based on C-banding analyses of A. sativa. Sanz et al. [17] proposed a FISH karyotype of the 21 chromosome pairs of A. sativa deduced from analyses using rDNA probes and satellite sequences specific to either the A or C-genome chromosomes. In the present study, we carried out the sequential C-banding and ND-FISH for the first time to the same metaphase cells of A. sativa BaiyanII (Fig. 4). The C-banding technique used here demonstrated that the C-genome chromosomes displayed strong staining because of accumulated heterochromatin (Fig. 4a). The specific distribution of $\mathrm{C}$-bands enabled most of the $\mathrm{A}$ and $\mathrm{D}$ genomes chromosomes to be clearly distinguished (Fig. 4a). The identical cell was subsequently confirm chromosome identification by ND-FISH using the above mentioned probes, including the oligo combinations of Oligo-oat-subtelo + Oligo-6C343 + Oligo-18SrDNA + Oligo-5SrDNA (Fig. 4b) and Oligo-6C51 + Oligo-8C355 (Fig. 4c). The results of C-banding and FISH patterns enabled us to combine the ND-FISH chromosome nomenclature for $A$. sativa used in the present study with the C-banding-based designations of Jellen et al. [10], and the FISH mapping study of Sanz et al. [17]. As shown in Table 2, the new nomenclature system allows 


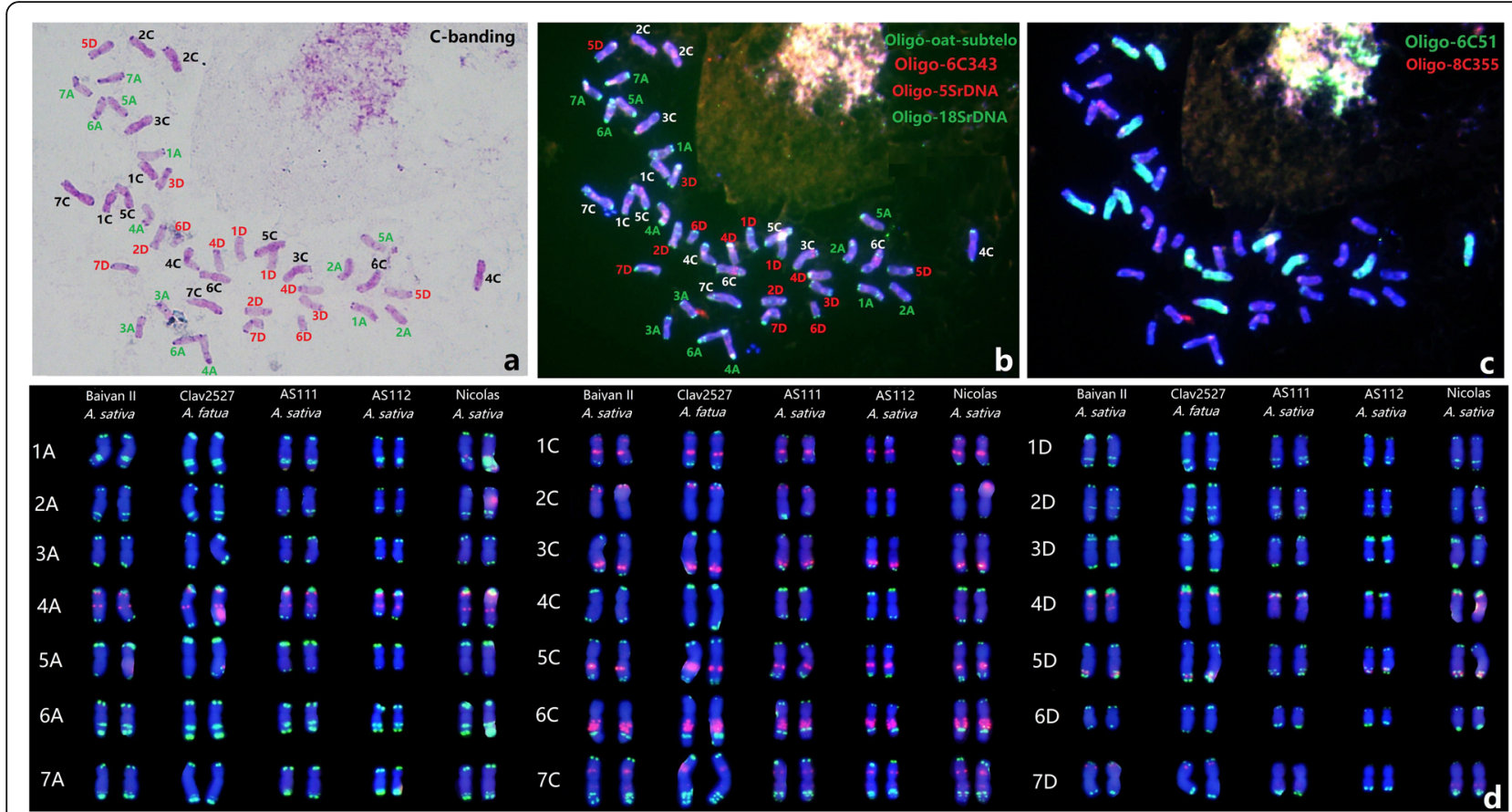

Fig. 4 The sequential C-banding (a) and FISH (b-d) for karyotyping hexaploid oat. The metaphase cell of Baiyanll was revealed by C-banding (a) and sequential FISH with the probes Oligo-oat-subtelo + Oligo-6C343 + Oligo-18SrDNA + Oligo-5SrDNA (b), Oligo-6C51 + Oligo-8C355 (c), respectively. The karyotype diagram of Oligo-oat-subtelo + Oligo-6C343 for Baiyanll, Clav2527, AS111, AS112 and Nicolas were indicated (d)

numbering of all of the 21 chromosome pairs of $A$. sativa based on genome assembly v1.

Our chromosome identification system, based on NDFISH with multiple probes, was used to develop karyotypes of the A. sativa lines BaiyanII, Clav2527, AS111, AS112 and Nicolas (Fig. 4). The proposed karyotype of hexaploid oat is also shown in Figure S2. We found that all five lines displayed identical karyotypes without any obvious translocations revealed by ND-FISH. Therefore, this new, uniform nomenclature system should be useful in oat cytogenetics, facilitating the identification of homeologous relationships among the chromosomes of the three sub-genomes in A. sativa.

\section{Integrated physical map for TR-Oligos in A. sativa}

FISH based on probes containing an SSR motif have been used for genomic evolutionary analysis [24, 43, 44]. However, the physical locations of these SSRs on the genomes of A. sativa were unavailable. Our established new karyotype nomenclature system based on FISH has enabled genome-wide localization of the SSRs repetitive sequences (Table 1) on common oat. The sequential NDFISH analysis has permited localization of several repeats onto specific regions of the chromosomes of BaiyanII (Figure S3). For example, we found that Oligo-(ACT) ${ }_{6}$ hybridized on the pericentromeric or centromeric regions of chromosomes $3 \mathrm{C}, 5 \mathrm{C}$ and $6 \mathrm{C}$, Oligo-(GAA) 7 on chromosomes $3 \mathrm{C}$ and $7 \mathrm{D}$, while Oligo-(CAA) $)_{7}$ showed strong signals on $6 \mathrm{~A}$ and $5 \mathrm{D}$, and weak signals on $1 \mathrm{~A}, 2 \mathrm{~A}, 5 \mathrm{~A}$, 2D of BaiyanII (Figure S3). The FISH hybridized sites of Oligo-(GAA $)_{7}$, Oligo-(CAA $)_{7}$ and Oligo- $(\mathrm{ACT})_{6}$ were consistent with previous reports on oat $[27,28,43,44]$. A total of 14 non-redundant oligo-probes (Table 1) and the SSR motifs were allocated to 223 predicted chromosome locations with an accumulated copy number over 40 per $1 \mathrm{Mb}$, which relatively matches with the physical locations revealed by ND-FISH. An integrated oligo-based NDFISH map of oat is shown in Fig. 5. The 223 hybridization sites include 66 on the A genome, 91 for the $\mathrm{C}$ genome and 66 in the D genome. Each chromosome appeared to have 3-19 hybridization sites, of which, the shortest chromosome 6D showed only three hybridization sites by two oligos (Fig. 5). The newly produced TR-Oligos, as well as previously reported probes (Table 1), can be used as an oligo 'cocktail' to detect specific chromosome regions effectively. The integrated FISH map will be extremely useful for detecting any chromosome rearrangements, as well as revealing their evolution by combined the genomic resources and cytogenetic knowledge of oat genome.

\section{Comparing the karyotype of $A$. sativa to wheat-barley lineage by Oligo-FISH painting}

The standard FISH karyotype based on the single copy sequences may illustrate the low variation among genomes which has been conserved across most of evolutionary history [22]. We used the lineage-specific probes 
Table 2 Comparative karyotype nomenclature system of the present genomic based system to those by C-banding, FISH analysis for A. sativa

\begin{tabular}{|c|c|c|c|c|}
\hline Genomes & Genome based chromosomes ${ }^{a}$ & $\begin{array}{l}\text { SSR based FISH } \\
\text { (Linares et al. [49]) }\end{array}$ & $\begin{array}{l}\text { C-banding } \\
\text { (Jellen et al. [10]) }\end{array}$ & $\begin{array}{l}\text { FISH and banding } \\
\text { (Sanz et al. [17]) }\end{array}$ \\
\hline \multirow[t]{7}{*}{ A } & $1 \mathrm{~A}$ & $5 \mathrm{~A}$ & 17 & $17 \mathrm{~A}$ \\
\hline & $2 \mathrm{~A}$ & $8 \mathrm{~A}$ & 8 & $8 \mathrm{~A}$ \\
\hline & $3 \mathrm{~A}$ & $18 \mathrm{~A}$ & 15 & $15 \mathrm{~A}$ \\
\hline & $4 \mathrm{~A}$ & $12 \mathrm{~A}$ & 19 & $19 \mathrm{~A}$ \\
\hline & $5 \mathrm{~A}$ & $20 \mathrm{~A}$ & 13 & $13 \mathrm{~A}$ \\
\hline & $6 \mathrm{~A}$ & $19 \mathrm{~A}$ & 16 & $16 \mathrm{~A}$ \\
\hline & $7 \mathrm{~A}$ & $6 \mathrm{~A}$ & 11 & $11 \mathrm{~A}$ \\
\hline \multirow[t]{7}{*}{ C } & $1 \mathrm{C}$ & $16 C$ & $16 C$ & $7 C$ \\
\hline & $2 \mathrm{C}$ & $1 \mathrm{C}$ & $2 \mathrm{C}$ & $1 \mathrm{C}$ \\
\hline & $3 \mathrm{C}$ & $4 C$ & $10 \mathrm{C}$ & $3 C$ \\
\hline & $4 \mathrm{C}$ & $15 C$ & $15 C$ & $6 C$ \\
\hline & $5 \mathrm{C}$ & $10 \mathrm{C}$ & $1 \mathrm{C}$ & $5 C$ \\
\hline & $6 \mathrm{C}$ & $7 \mathrm{C}$ & $7 \mathrm{C}$ & $4 \mathrm{C}$ \\
\hline & $7 \mathrm{C}$ & $2 \mathrm{C}$ & $4 C$ & $2 \mathrm{C}$ \\
\hline \multirow[t]{7}{*}{ D } & 1D & $10 D$ & $11 \mathrm{D}$ & $10 \mathrm{D}$ \\
\hline & $2 D$ & $12 \mathrm{D}$ & $9 D$ & $12 \mathrm{D}$ \\
\hline & 3D & $14 \mathrm{D}$ & $14 \mathrm{D}$ & $14 \mathrm{D}$ \\
\hline & 4D & $9 D$ & $17 D$ & $9 D$ \\
\hline & $5 \mathrm{D}$ & $18 D$ & $21 \mathrm{D}$ & $18 D$ \\
\hline & $6 \mathrm{D}$ & $21 \mathrm{D}$ & $13 D$ & $21 \mathrm{D}$ \\
\hline & 7D & $20 D$ & $3 D$ & $20 D$ \\
\hline
\end{tabular}

a The present nomenclature of chromosomes $1 \mathrm{~A}$ to $7 \mathrm{D}$ was according to the designation of oat reference assembly v1

Synt1 to Synt7 representing syntenic regions between wheat and barley [37] to compare the linkage group assignment of $A$. sativa chromosomes to Triticeae species. For example, the probe Synt7 produced strong hybrid signals on the three chromosomes pairs of $7 \mathrm{~A}, 7 \mathrm{~B}$ and $7 \mathrm{D}$ of wheat, and barley $7 \mathrm{H}$, as well as the linkage group 7 chromosomes of other Triticeae species [37]. Mitotic chromosomes of $A$. sativa were subjected to ND-FISH analysis using probe combinations of Oligo-6C51+ Oligo-8C355 (Fig. 6a) and Oligo-oat-subtelo + Oligo6c343 + Oligo-18SrDNA + Oligo-5SrDNA (Fig. 6b), followed FISH by the bulked oligo probes Synt1 to Synt7 (Fig. 6). The hybridization patterns showed that Synt1 produced strong hybrid signals on the three chromosomes pairs of $1 \mathrm{~A}, 1 \mathrm{C}$ and $1 \mathrm{D}$ of the $A$. sativa group 1 chromosomes, while Synt7 produced strong hybrid signals on the three chromosomes pairs of $7 \mathrm{~A}, 7 \mathrm{C}$ and 7D of the A. sativa group 7 chromosomes, respectively. Similarly, the bulked painting probes Synt6 (Fig. 6), Synt 2 and Synt3 (data not shown) also mainly hybridized to corresponding linkage groups 6, 2 and 3 of oat chromosomes, respectively. We also observed that Synt4 and Synt 5 hybridized to six chromosome pairs of $A$. sativa on the ends of both long and short arms, indicating that oat linkage groups 4 and 5 have undergone clear rearrangements with respect to the wheat-barley chromosome linkage groups (Fig. 6c). The results confirmed the genome synteny of the putative Hordeum-Avena orthologs by cytogenetic ND-FISH and Oligo-FISH painting, which is consistent to the prediction by Maughan et al. [35]. Therefore, our comparative bulk probe based-FISH results have demonstrated the relatively conserved collinearity of the grass genomes, and confirmed the universal karyotype system we have established as potentially useful for comparative evolutionary studies.

\section{The karyotype system applied for diploid Avena chromosome identification}

Maughan et al. [35] designated the chromosomes AA1AA7 and AE1-AE7 for the As- and Cp-subgenomes from $A$. atlantica and $A$. eriantha, respectively. The physical locations of the probes Oligo-3A352 + Oligo-4A70 were used to study the genomes of diploid Avena species. NDFISH also revealed the karyotypes of $A$. brevis, $A$. wiestti and $A$. nuda (Fig. 7d). We found that the physical distribution of the probes on AA1 to AA7 chromosomes closely matched their locations revealed by ND-FISH on the A genome of A. sativa. Similarly, for A. venticosa, the 


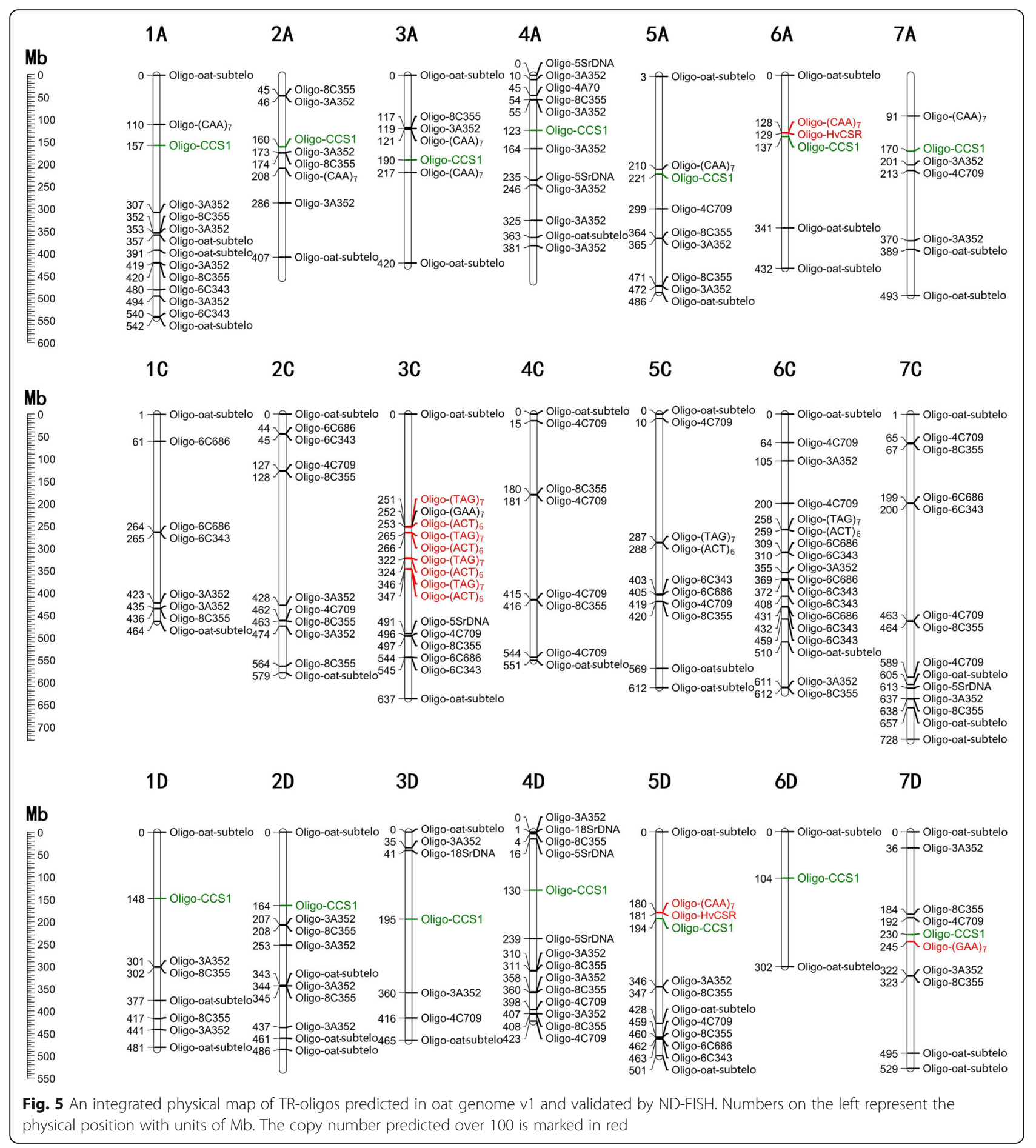

physical locations of probes Oligo-oat-subtelo + Oligo6C343 on the $\mathrm{C}$ genome were consistent with the NDFISH results on A. sativa (Fig. 7). Chromosomes AE5, AE4, AE3, AE7, AE6, AE2, AE1 were corresponded to the linkage groups 1-7 C, respectively (Fig. 7 g).

The bulked oligos Synt1 to Synt7, developed previously for FISH painting of wheat-barley chromosomes, can also be applied to the A genome chromosomes of
Avena to reveal structural rearrangements. FISH results showed that chromosomes 1 A (AA2), 3 A (AA3) and 7 A (AA1) were structurally highly conserved (Fig. 8). Chromosomes 2 A (AA5), 4 A (AA4), 5 A (AA6) and 6 A (AA7) displayed distinct rearrangements, based on FISH with Synt1 and Synt7 probes combined with the ND-FISH by probes Oligo-4A70 and Oligo-3A352 (Fig. 8). 

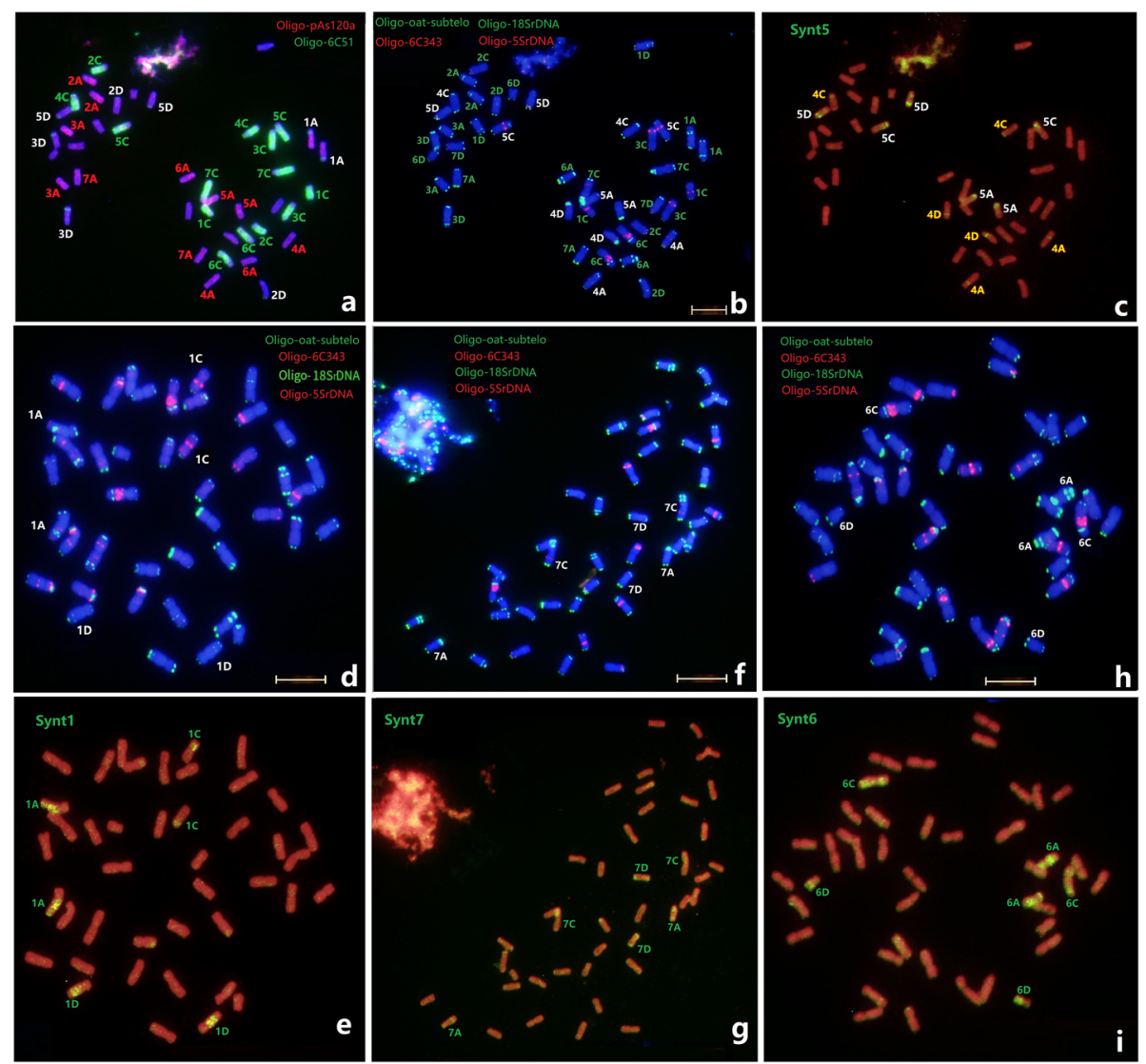

Fig. 6 Sequential FISH of Avena sativa with repetitive probes and Oligo pools. The probes Oligo-pAs120a + Oligo-6C51 (a), Oligo-oat-subtelo + Oligo-6C343 + Oligo-18SrDNA + Oligo-5SrDNA (b, d, f, h), Synt5 (c), Synt1 (e), Synt7 (g), and Synt6 (i) were used, respectively

Identification of chromosome rearrangements in A. sativa Metaphase chromosome spreads of $A$. sativa selected lines AS112-1 and AS112-3 were subjected to sequential ND-FISH using multiple oligo probes. ND-FISH revealed that line AS112-1 contained a 7D-2 C reciprocal translocation on the interstitial region of the short arm of the original 7D and long arm of $2 \mathrm{C}$ chromosomes (Fig. 9a-e). Line AS112-3 contained multiple translocations involving 5C-3C, $1 \mathrm{D}-7 \mathrm{C}$ and $7 \mathrm{~A}-4 \mathrm{C}$ as well as dicentric and deletion chromosomes, which are identified by sequential FISH. The breakage points on the deletion, translocation, dicentric chromosomes and short midget chromosomes are shown in Fig. 9f-h. These complex chromosome rearrangements can be easily identified by several rounds of FISH with the above probes, and also with help of the established standard chromosome nomenclatures. Therefore, advanced karyotypic analysis by sequential ND-FISH on Avena species is effective for identifying new chromosome translocations and visualizing the precise breakpoints of the chromosomal rearrangements.

\section{Discussion}

Standard karyotypes are generally accompanied by a universally accepted nomenclature system wherein individual chromosomes and specific regions can be numerically recognized, which provides a quick and reliable mode of discerning cross-species chromosomal or genomic similarities [21]. Traditionally, aneuploid analysis combined with individual chromosome identification has been used to assign a chromosome to a specific linkage group in diploid and polyploid plant species [22]. In hexaploid oat, the 21 distinct monosomic lines based on differences in chromosome morphology have been described [51]. Such aneuploid stocks include monosomic lines that can be difficult to maintain [6]. The development of chromosome banding techniques has long been considered as a fast, reliable, and economical method for identification of chromosomes of the Avena species [6, 12, 16]. However, some chromosomes or chromosome segments are lacking of diagnostic bands. Subsequently, Irigoyen et al. [15] generated a FISH map of A. sativa cv. SunII and its monosomic lines. They used simultaneous 

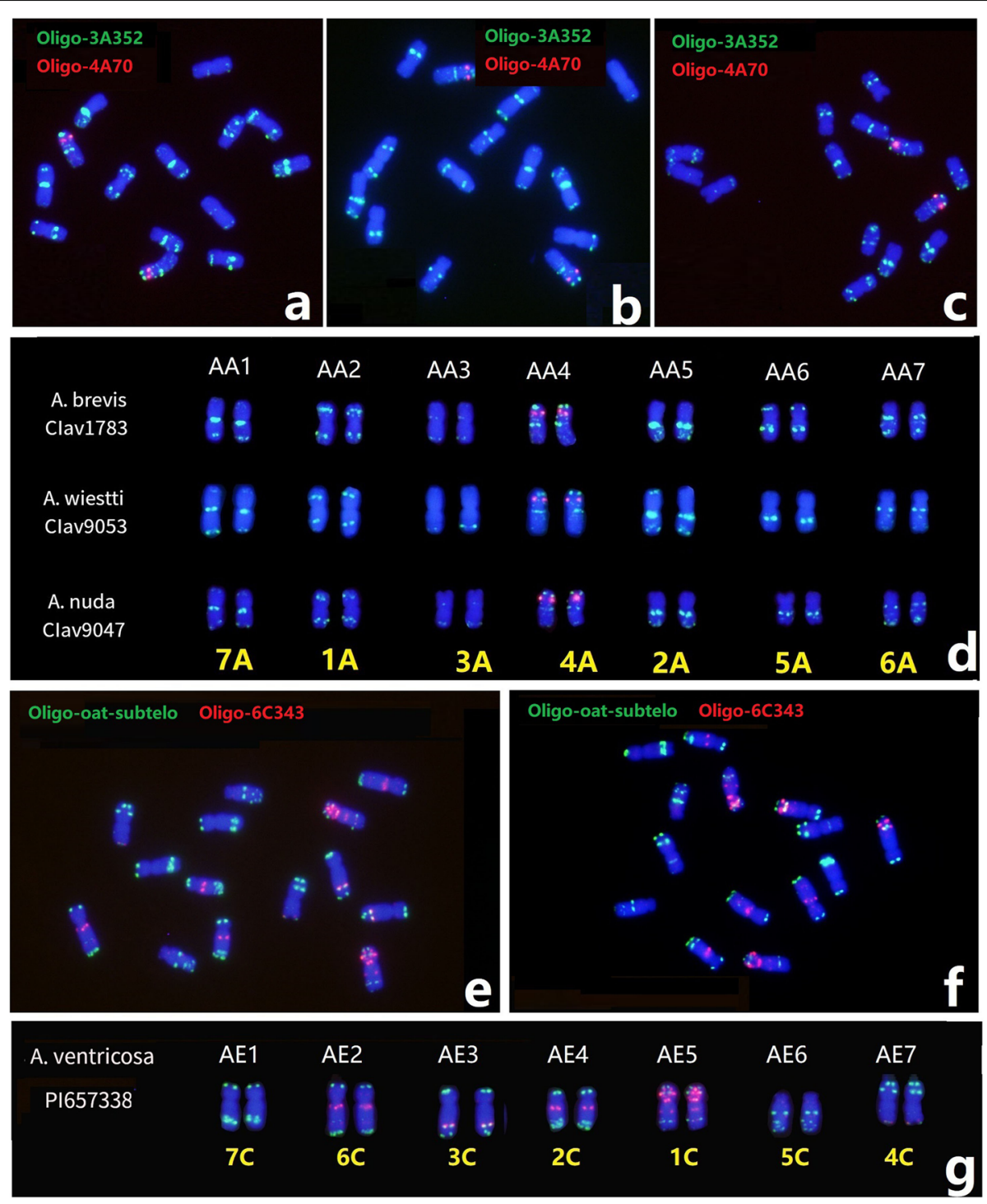

Fig. 7 ND-FISH karyotype of diploid Avena species with A and C genomes by multiple oligo probes. The ND-FISH of A. brevis (a), A. wiestti (b), A. nuda (c) by Oligo-3A352 + Oligo-4A70, and A. ventricosa (e, f) by Oligo-oat-subtelo + Oligo-6C343, respectively. The ND-FISH karyotypes of Oligo3 A352 and Oligo-4A70 for above lines were showed with the predicted chromosomes (d) and (g), respectively

and sequential FISH which allowed the unequivocal identification and genome assignation of all chromosomes, including three intergenomic translocations in SunII. In light of the fact that an average Avena genome may contain about $76-78 \%$ dispersed or tandem distribution of repetitive DNA sequences, Liu et al. [30] identified the nature, abundance and organization of all the repetitive DNA families in A. sativa, and they produced several probes suitable for use in FISH. Conventional FISH and ND-FISH methods are mostly based on the satellite repetitive sequences and are generally not linkage group-specific $[7,14,19,20]$. Consequently, a highresolution cytogenetic FISH map of the universal hexaploid and diploid Avena genome representing each of its chromosomes is essential for precise chromosome identification.

The increasing amount of available sequence data of both diploid and hexaploid oat has led to greater knowledge of the abundance and distribution of repeatsequences across the assembled genomes of these types of species [35]. In the present study, we predicted the genome-wide tandem repeats for OT3098 genome assembly v1 by accessing data on the B2DSC web server [25], and produced seven new oligo probes which hybridized onto the chromosomes of oat (Table 1). that the TR-based Oligo probes, such as combinations of Oligo-6C51 + Oligo-8C355 and Oligo-oat-subtelo + Oligo-6C343 + Oligo-18SrDNA + Oligo-5SrDNA (Figs. 4 

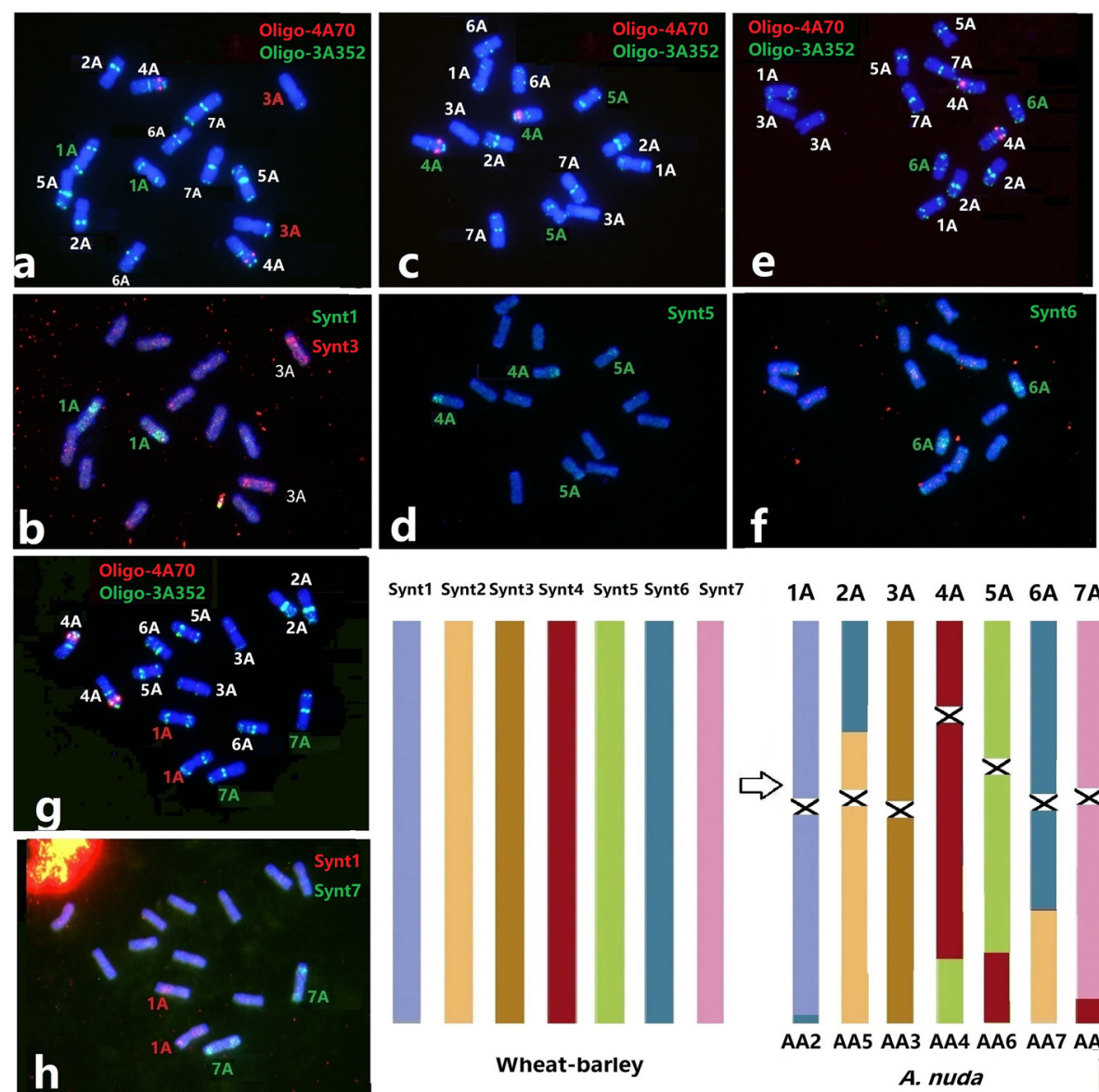

Synt1 Synt2 Synt3 Synt4 Synt5 Synt6 Synt7

1A 2A $3 A \quad 4 A \quad 5 A \quad 6 A \quad 7 A$

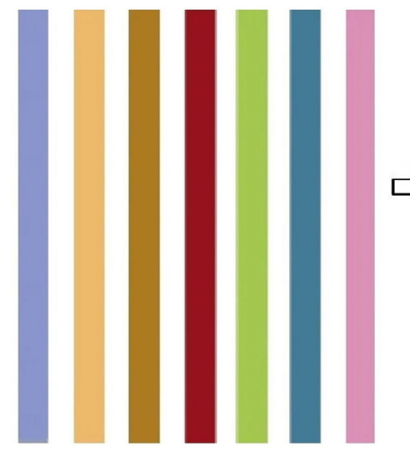

Wheat-barley

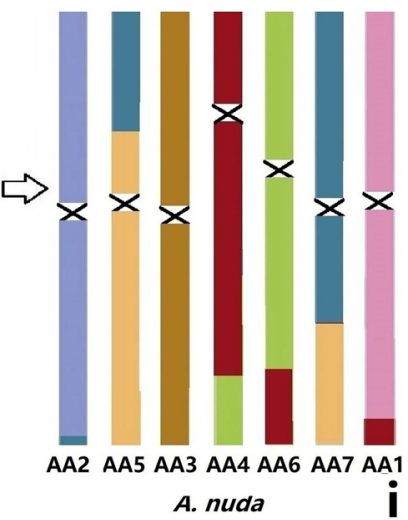

Fig. $8 \mathrm{FISH}$ of bulked oligo probes and the TR based Oligos for A. nuda accession Clav 1783. Hybridization with probes Oligo-4A70 + Oligo-3A352 $(\mathbf{a}, \mathbf{c}, \mathbf{e}, \mathbf{g})$ and subsequent stripping and re-hybridization with the bulked oligo pools Synt1 + Synt3 (b), Synt5 (d), Synt6 (f) and Synt1 + Synt7 (h) are shown. i A putative schematic diagram showing the A genome of diploid Avena compared with the common ancestor of wheat and barley

and 6), enable the precise and efficient identification of hexaploid oat chromosomes. The advantage of the present chromosome identification system is that it employs sequential ND-FISH with an increased number of probes which exhibit clear locations. Our procedure will improve the reliability for chromosome identification (Fig. 5), and the resolution can thus be increased by the ongoing updated version of oat genome assembly. We have also investigated the degree of repetitive DNA composition in genomes from the wild relatives of oat by ND-FISH (Fig. 7). Future research will extend this study to a number of other diploid and tetraploid species for quantifying the magnitude of intra- and interspecific variation.

The time periods for divergence between oats and members of the Triticeae (wheat, barley) has been estimated to be 25.5- 26.5 MYA between oats and wheat, and 23-25 MYA between oats and barley [40]. Wholegenome comparisons with barley and wheat have revealed that extensive blocks of synteny remain which have helped resolve homologous relationships between different oat linkage groups [32]. The wheat-barley genome sequences will be useful resources to assist genetic and genomic researches in oat $[30,35]$. Based on the comparative FISH between diploid and hexaploid oat by Oligo-FISH painting with probes Synt1 to Synt7 (Fig. 6), we found that the comparative maps may help to resolve homologous relationships between different linkage groups and reveal many undiscovered major rearrangements in Avena subgenomes. Moreover, the estimated time of divergence of the two more similar subgenomes (A/D) from the distinct one (C) was around 7.9-8.7 MYA [40]. It also possibly suggests that large chromosome structural rearrangements may have occurred between diploid and hexaploid Avena species, as revealed by genome-wide comparisons between the $\mathrm{As}$ and $\mathrm{Cv}$ genomes of diploid species to those of $\mathrm{A}$ and $\mathrm{C}$ genomes of the hexaploid oat (Figure S4). The comparative bulked probes based FISH results showed the overall relatively conserved genome collinearity of the Avena species across the different ploidy levels (Figs. 6 and 8). Our results demonstrated that the development of region- 

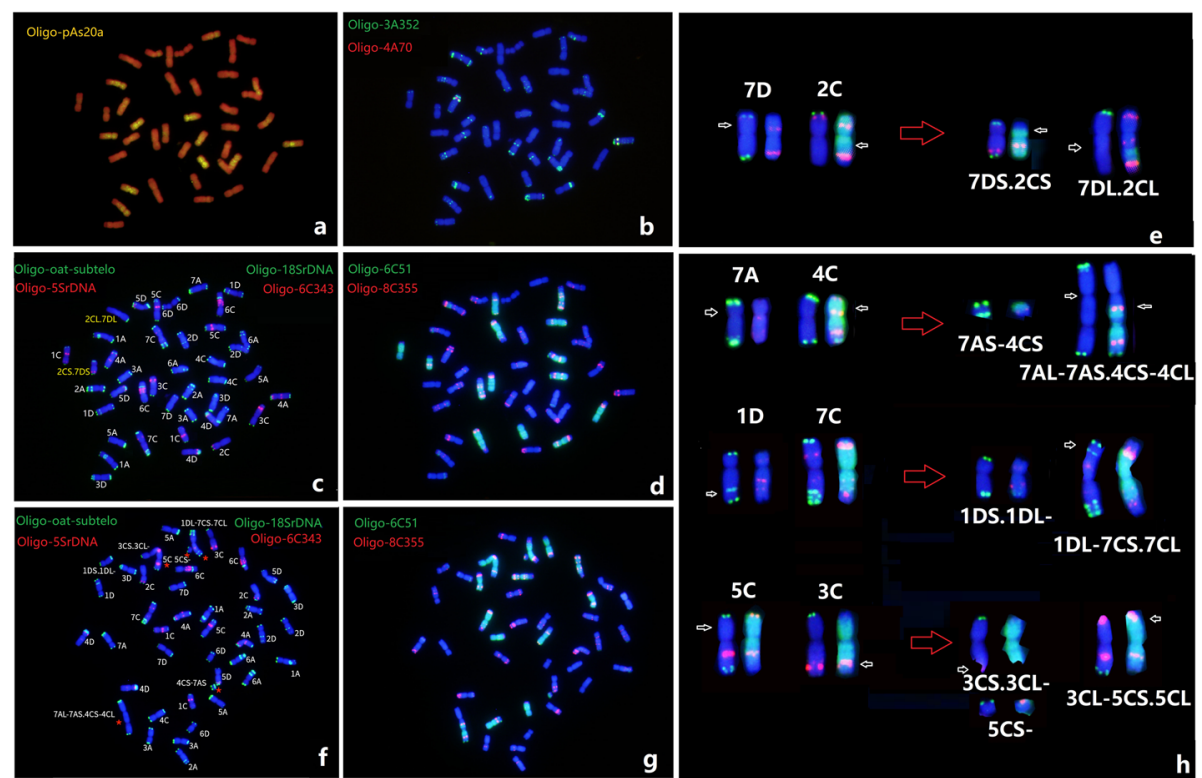

Fig. 9 Sequential FISH karyotyping of root-tip cell from A. sativa lines AS112-1 (a-e) and AS112-3 (f-h) revealed multiple intergenomic translocations. The probes Oligo-pAs120 (a), Oligo-3A352 + Oligo-4A70 (b), Oligo-oat-subtelo + Oligo-6C343 + Oligo-18SrDNA + Oligo-5SrDNA (c, f), Oligo-6C51 + Oligo-8C355 (d, g), respectively. The karyotype diagrams after ND-FISH using probes Oligo-oat-subtelo + Oligo-6C343 + Oligo18SrDNA + Oligo-5SrDNA (left), Oligo-6C51 + Oligo-8C355 (right) indicate numerous breakage points on the original oat chromosomes, as shown by arrows $(\mathbf{e}, \mathbf{h})$. Chromosome structural changes in these two lines was deduced by referring to chromosome structures of $A$. sativa

specific Oligo-FISH probes based on oat sequences is useful to identify individual homoeologous chromosomes from distantly Avena species. The present comparative oligo-based FISH studies and later development of more dense landmarks will provide new insights into the evolution of Avena genera.

In addition, the lack of a high-density marker system has limited the application of genomic selection in cultivated oat. The accuracy of genomic selection has continually increased since the linkage maps have been improved by genetic, cytogenetic and genomic advances [52]. Chaffin et al. [18] published a map representing the most common physical chromosome arrangements in oat. Deviations from the consensus map may indicate physical rearrangements and large chromosomal translocations may vary among different varieties. The present system has enabled precise definition of breakpoints of translocation chromosomes (Fig. 9), which has great potential for the high-throughput karyotyping of the chromosome structure for evolutionary diverged genomes. Some FISH probes specifically hybridized to oat and produced no hybridization signals in wheat and other grass species. Therefore, our FISH protocol may have additional applications in tracing Avena chromatin introgressed into wheat or maize $[46,53,54]$ following wide crosses and chromosome manipulation based breeding practices.

\section{Methods}

\section{Plant materials}

The Clav and PI accessions of wild and cultivated Avena accessions were provided by United States Department of Agriculture, Agricultural Research Service. The cultivated oat lines BaiyanII and AAC Nicolas were maintained in Shanxi Agricultural University, China. Seeds of natural accessions of hexaploid oat lines AS111 and AS112 were maintained in the Laboratory of Molecular and Cell Biology, Center for Informational Biology, School of Life Science and Technology, University of Electronic Science and Technology of China in Chengdu. The materials and their chromosome constitution are listed in Table 3.

\section{Bioinformatic analysis of repeats in Avena genome}

The genome sequences, including diploid oat [35] and cultivated oat OT3098 reference assembly v1 (https:// wheat.pw.usda.gov/GG3/graingenes_downloads/oat-ot3 098-pepsico) were download for prediction of tandem repeats using the TRF software [55]. The physical locations of tandem repeats was according to the B2DSC method with default parameters (http://mcgb.uestc.cn/ b2dsc) described by Lang et al. [25]. Thirteen novel oligo probes with physical location in Avena genomes for NDFISH were designed and listed in Table 1. 
Table 3 Materials and their genome constitution used in this research

\begin{tabular}{|c|c|c|c|c|c|}
\hline No & Taxa & Voucher (Repository) & Origin country & $2 n$ & Genome(s) \\
\hline 1 & A. brevis Roth & Clav 1783 (NSGC) & Niedersachsen, Germany & 14 & As \\
\hline 2 & A. nuda L. & Clav 9047 (NSGC) & England, United Kingdom & 14 & As \\
\hline 3 & A. wiestii Steud. & Clav 9053 (NSGC) & Ontario, Canada & 14 & As \\
\hline 4 & A. ventricosa Balansa ex Coss. & PI 657,338 (NSGC) & Morocco & 14 & Cv \\
\hline 5 & A. eriantha Durieu & PI367381 (NSGC) & Madrid, Spain & 14 & $\mathrm{Cp}$ \\
\hline 6 & A. fatua $\mathrm{L}$. & Clav 2527 (NSGC) & Alberta, Canada & 42 & ACD \\
\hline 7 & A. sativa $\mathrm{L}$. & Baiyan II (SXAU) & Jilin, China & 42 & ACD \\
\hline 8 & A. sativa $\mathrm{L}$. & AAC Nicolas (ORDC) & Ottawa, Canada & 42 & ACD \\
\hline 9 & A. sativa $\mathrm{L}$. & Clav 3520 (NSGC) & Germany & 42 & ACD \\
\hline 10 & A. sativa $\mathrm{L}$. & AS111 (UESTC) & Shanxi, China & 42 & $A C D$ \\
\hline 11 & A. sativa $\mathrm{L}$. & AS112 (UESTC) & Shanxi, China & 42 & $A C D$ \\
\hline
\end{tabular}

Voucher: PI or Clav, Germplasm Resources Information Network of United States Department of Agriculture at Beltsville, USA; NSGC, National Small Grains Collection, USA; SXAU, Shanxi Agricultural University, China; ORDC, Ottawa Research and Development Centre, Canada; UESTC, University of Electronic Science and Technology of China. Genome assignment based on Liu et al. [8]

\section{Chromosome preparation, Sequential C-banding and FISH analysis}

Root tips from germinated seeds were collected and treated with nitrous oxide followed by enzyme digestion [56]. The Giemsa C-banding was done according to according to Li et al. [57]. The TR based probes with the synthetic oligos were labeled with either 5 ' end-labelled 6-carboxyfluorescein (6-Fam) for green or 6carboxytetramethylrhodamine (Tamra) for red signals. The protocol of non-denaturing FISH (ND-FISH) using synthesized probes was described by $\mathrm{Fu}$ et al. [58]. The wheat-barley linkage group specific bulked oligo pool probes (Synt1 to Synt 7) were designed following our recently published procedure [37]. After oligo-based FISH, sequential FISH painting with oligo pool probes was conducted according to Han et al. [38] and Bi et al. [59]. Photomicrographs were taken with an Olympus BX-53 microscope equipped with a DP-70 CCD camera.

\section{Conclusions}

The availability of the Oligo-based FISH system opens the way in the genus Avena for comprehensive cytogenetic analysis combined with genomics tools. We have demonstrated that ND-FISH with a new set of tandem repeat probes, combined with FISH painting by oligo pools, can generate a high resolution and informative cytogenetic map on genome regions for the cultivated oat. The consensus karyotype based on ND-FISH, by physical mapping of labeled probes, can effectively substitute for traditional cytological methods in Avena for identifying genomic rearrangements. Our current cytogenetic mapping efforts, integrated with genomic approaches, will provide a new perspective to address important questions involving chromosome evolution in Avena species, as well as wide-cross and chromosome manipulation-based breeding in oat.

\section{Supplementary Information}

The online version contains supplementary material available at https://doi. org/10.1186/s12870-021-02999-3.

Additional file 1: Table S1. The predicted total TRs in the chromosomes of oat genome assembly $v 1$ by TRF., Table S2. Distribution and copy number prediction of centromeric repeats OligoCCS1 in oat genome assembly v1., Figure S1. The genomic distribution of TRs in assembled oat genome $v 1$ revealed by each chromosome., Figure S2. ND-FISH karyotype of A. sativa revealed by multiple oligo probes of tandem repeats., Figure S3. Sequential ND-FISH analysis by predicted TR Oligo-probes on metaphase chromosomes of oat Baiyanll., Figure S4. The comparative genome between the A-genome of A. sativa to Agenome of A. atlantica (a), C-genome of A. sativa to AE genome of A. eriantha (b) by Circos software with the annotated genes.

\section{Acknowledgements}

We are thankful to Dr. lan Dundas at the University of Adelaide, Australia for reviewing the manuscript, and Dr. Tao Lang at the Sichuan Academy of Agriculture Sciences for comments on analysis of tandem repeats.

\section{Authors' contributions}

Z.Y., G.L. and J.J. designed the research; W.J., G.L., C.J., W.Y., W.Z., Z.F., Y.L. performed experiments; Z.Y. and J.J. analyzed the data; Z.Y., J.J. and G.L. wrote the manuscript. All authors read and approved the final manuscript.

\section{Funding}

This work was financially supported by National Key Research and Development Program of China (2016YFD0102000), Key Research and Development Program of Shanxi Province (201903D221073); Research Project Supported by Shanxi Scholarship Council of China (2020-067) and National Natural Science Foundation of China (No. 31971886).

\section{Availability of data and materials}

The data that support the findings of this study are included in this published article and its additional files.

\section{Declarations}

\section{Ethics approval and consent to participate}

We complied with all relevant institutional, national and international guidelines and the appropriate permissions for PI and Clav materials and all Avena species.

Consent for publication

Not applicable. 


\section{Competing interests}

The authors declare that they have no competing interest.

Received: 11 February 2021 Accepted: 28 April 2021 Published online: 12 May 2021

\section{References}

1. Mark B, Andon JW. State of the art reviews: the oatmeal-cholesterol connection: 10 years later. Medicine AJAJoL. 2008;2(1):51-7.

2. Agostoni C, Bresson J, Fairweather-Tait S, Flynn A, Golly I, Korhonen H, Lagiou P, Løvik M, Marchelli R, Martin A, Moseley B, Neuhäuser-Berthold M, Przyrembel H, Salminen S, Sanz Y, Strain S, Strobel S, Tetens I, Tomé D, Loveren $\mathrm{H}$, Verhagen $\mathrm{H}$. Scientific opinion on the substantiation of a health claim related to oat beta glucan and lowering blood cholesterol and reduced risk of (coronary) heart disease pursuant to Article 14 of Regulation (EC) No 1924/2006. EFSA Journal. 2010;8(12): 1885.

3. Rajhathy T, Thomas H. Cytogenetics of Oats; Miscellaneous Publication of the Genetics Society of Canada: Ottawa, 1974, 1-90.

4. Zhou X, Jellen EN, Murphy JP. Progenitor germplasm of domesticated hexaploid oat. Crop Sci. 1999;39(4):1208-14.

5. Yan $\mathrm{H}$, Bekele WA, Wight $\mathrm{CP}$, Peng $\mathrm{Y}$, Langdon $\mathrm{T}$, Latta RG, et al. Highdensity marker profiling confirms ancestral genomes of Avena species and identifies D-genome chromosomes of hexaploid oat. Theor Appl Genet. 2016;129(11):2133-49.

6. Thomas H. Cytogenetics of Avena; in Oat Science and Technology, eds. Marshall, H. G. \& Sorrells, M. E. (American Society of Agronomy and Crop Science Society of America, Madison, WI), 1992, 473-507.

7. Katsiotis A, Loukas M, Heslop-Harrison JS. Repetitive DNA, genome and species relationships in Avena and Arrhenatherum (Poaceae). Ann BotLondon. 2000;86(6):1135-42.

8. Liu Q, Lin L, Zhou X, Peterson PM, Wen J. Unraveling the evolutionary dynamics of ancient and recent polyploidization events in Avena (Poaceae). Sci Rep. 2017:7:41944.

9. Jellen EN, Rooney WL, Phillips RL, Rines HW. Characterization of the hexaploid oat Avena byzantina cv. Kanota monosomic series using Cbanding and RFLPs. Genome. 1993;36(5):962-70.

10. Jellen EN, Rines HW, Fox SL, Davis DW, Phillips RL, Gill BS. Characterization of 'Sun II' oat monosomics through C-banding and identification of eight new 'Sun II' monosomics. Theor Appl Genet. 1997;95(8):1190-5.

11. Chen $\mathrm{Q}$, Armstrong K. Genomic in situ hybridization in Avena sativa. Genome. 1994;37(4):607-12.

12. Jellen E, Leggett JM. Cytogenetic manipulation in oat improvement; In Genetic resources, chromosome engineering, and crop improvement. Vol. 2. Cereals. Edited by R.J. Singh and P.P. Jauhar. Boca Raton: CRC Press. 2006,199-232

13. Badaeva ED, Shelukhina OY, Goryunova SV, Loskutov IG, Pukhalskiy VA. Phylogenetic relationships of tetraploid AB-genome Avena species evaluated by means of cytogenetic (C-banding and FISH) and RAPD analyses. Journal of Botany. 2010;2010:742307.

14. Fominaya A, Hueros G, Loarce Y, Ferrer E. Chromosomal distribution of a repeated DNA sequence from C-genome heterochromatin and the identification of a new ribosomal DNA locus in the Avena genus. Genome. 1995;38(3):548-57.

15. Irigoyen $\mathrm{ML}$, Linares $\mathrm{C}$, Ferrer $\mathrm{E}$, Fominaya A. Fluorescence in situ hybridization mapping of Avena sativa L. CV. Sunll and its monosomic lines using cloned repetitive DNA sequences. Genome. 2002;45(6):1230-7.

16. Jellen EN, Gill BS, Cox TS. Genomic in situ hybridization differentiates between A/D-genome and C-genome chromatin and detects intergenomic translocations in polyploid oat species (genus Avena). Genome. 1994;37(4): 613-8.

17. Sanz $\mathrm{MJ}$, Jellen $\mathrm{EN}$, Loarce $\mathrm{Y}$, Irigoyen $\mathrm{ML}$, Ferrer E, Fominaya A. A new chromosome nomenclature system for oat (Avena sativa L. and A. byzantina C. Koch) based on FISH analysis of monosomic lines. Theor Appl Genet. 2010;121(8):1541-52.

18. Chaffin AS, Huang YF, Smith S, Bekele WA, Babiker E, Gnanesh BN, et al. A consensus map in cultivated hexaploid oat reveals conserved grass synteny with substantial subgenome rearrangement. Plant Genome. 2016;9(2):1-21.

19. Tomas D, Rodrigues J, Varela A, Veloso MM, Viegas W, Silva M. Use of repetitive sequences for molecular and cytogenetic characterization of Avena species from Portugal. Int J Mol Sci. 2016;17(2): 203.
20. Fominaya A, Loarce Y, Montes A, Ferrer E. Chromosomal distribution patterns of the $(\mathrm{AC})_{10}$ microsatellite and other repetitive sequences, and their use in chromosome rearrangement analysis of species of the genus Avena. Genome. 2017:60(3):216-27.

21. Jiang J, Gill BS. Nonisotopic in situ hybridization and plant genome mapping: the first 10 years. Genome. 1994;37(5):717-25.

22. Jiang J. Fluorescence in situ hybridization in plants: recent developments and future applications. Chromosome Res. 2019;27(3):153-65.

23. Tang Z, Yang Z, Fu S. Oligonucleotides replacing the roles of repetitive sequences pAs1, pSc1 19.2, pTa-535, pTa71, CCS1, and pAWRC.1 for FISH analysis. J Appl Genet. 2014;55(3):313-8.

24. Cuadrado Á, Jouve N. Chromosomal detection of simple sequence repeats (SSRS) using nondenaturing FISH (ND-FISH). Chromosoma. 2010; 119(5): 495-503.

25. Lang T, Li G, Wang H, Yu Z, Chen Q, Yang E, et al. Physical location of tandem repeats in the wheat genome and application for chromosome identification. Planta. 2019;249(3):663-75.

26. Xi W, Tang Z, Tang S, Yang Z, Luo J, Fu S. New ND-FISH-positive Oligo probes for identifying Thinopyrum chromosomes in wheat backgrounds. Int J Mol Sci. 2019;20(8): 2031.

27. Luo XM, Tinker NA, Zhou YH, Liu JC, Wan WL, Chen L. A comparative cytogenetic study of 17 Avena species using Am1 and (GAA) 6 oligonucleotide FISH probes. Acta Physiol Plant. 2018:40(8):145.

28. Luo XM, Tinker NA, Zhou YH, Liu JC, Wan WL, Chen L. Chromosomal distributions of oligo-Am1 and (TTG)6 trinucleotide and their utilization in genome association analysis of sixteen Avena species. Genet Resour Crop Evol. 2018:65(6):1625-35.

29. Luo XM, Tinker NA, Zhou YH, Wight CP, Liu JC, Wan WL, et al. Genomic relationships among sixteen species of Avena based on $(A C T)_{6}$ trinucleotide repeat FISH. Genome. 2018;61(1):63-70.

30. Liu Q, Li X, Zhou X, Li M, Zhang F, Schwarzacher T, et al. The repetitive DNA landscape in Avena (Poaceae): chromosome and genome evolution defined by major repeat classes in whole-genome sequence reads. BMC Plant Biol. 2019:19(1):226.

31. Yan H, Ren Z, Deng D, Yang K, Yang C, Zhou P, et al. New evidence confirming the CD genomic constitutions of the tetraploid Avena species in the section Pachycarpa Baum. PLoS One. 2021;16(1):e0240703.

32. Gutierrez-Gonzalez JJ, Garvin DF. Reference genome-directed resolution of homologous and homeologous relationships within and between different oat linkage maps. Plant Genome. 2011:4(3):178-90.

33. Macas J, Neumann P, Novak P, Jiang J. Global sequence characterization of rice centromeric satellite based on oligomer frequency analysis in largescale sequencing data. Bioinformatics. 2010;26(17):2101-8.

34. Luo MC, Gu YQ, Puiu D, Wang H, Twardziok SO, Deal KR, et al. Genome sequence of the progenitor of the wheat $\mathrm{D}$ genome Aegilops tauschii. Nature. 2017;551(7681):498-502.

35. Maughan PJ, Lee R, Walstead R, Vickerstaff RJ, Fogarty MC, Brouwer CR, et al. Genomic insights from the first chromosome-scale assemblies of oat (Avena spp.) diploid species. BMC Biol. 2019;17(1):92.

36. Pavlek M, Gelfand Y, Plohl M, Mestrovic N. Genome-wide analysis of tandem repeats in Tribolium castaneum genome reveals abundant and highly dynamic tandem repeat families with satellite DNA features in euchromatic chromosomal arms. DNA Res. 2015;22(6):387-401.

37. Li G, Zhang T, Yu Z, Wang H, Yang E, Yang Z. An efficient Oligo-FISH painting system for revealing chromosome rearrangements and polyploidization in Triticeae. Plant J. 2021;105(4):978-93.

38. Han YH, Zhang T, Thammapichai P, Weng YQ, Jiang JM. Chromosomespecific painting in Cucumis species using bulked oligonucleotides. Genetics. 2015;200(3):771-9.

39. Braz GT, He L, Zhao H, Zhang T, Semrau K, Rouillard JM, et al. Comparative Oligo-FISH mapping: an efficient and powerful methodology to reveal karyotypic and chromosomal evolution. Genetics. 2018;208(2):513-23.

40. Gutierrez-Gonzalez JJ, Garvin DF. Subgenome-specific assembly of vitamin E biosynthesis genes and expression patterns during seed development provide insight into the evolution of oat genome. Plant Biotechnol J. 2016; 14(11):2147-57.

41. Katsiotis A, Hagidimitriou M, HeslopHarrison JS. The close relationship between the $A$ and $B$ genomes in Avena $L$ (Poaceae) determined by molecular cytogenetic analysis of total genomic, tandemly and dispersed repetitive DNA sequences. Ann Bot-London. 1997;79(2):103-9. 
42. Roser M, Winterfeld G, Grebenstein B, Hemleben V. Molecular diversity and physical mapping of $5 \mathrm{~S}$ rDNA in wild and cultivated oat grasses (Poaceae: Aveneae). Mol Phylogenet Evol 2001;21(2):198-217.

43. Luo $X$, Zhang $H$, Kang $H$, Fan $X$, Wang $Y$, Sha $L$, et al. Exploring the origin of the $D$ genome of oat by fluorescence in situ hybridization. Genome. 2014; 57(9):469-72.

44. Luo XM, Tinker NA, Zhang HQ, Wight CP, Kang HY, Fan X, et al. Centromeric position and genomic allocation of a repetitive sequence isolated from chromosome 18D of hexaploid oat, Avena sativa L. Genet Resour Crop Evol. 2015;62(1):1-4

45. Jiang J, Nasuda S, Dong F, Scherrer CW, Woo SS, Wing RA, et al. A conserved repetitive DNA element located in the centromeres of cereal chromosomes. Proc Natl Acad Sci U S A. 1996;93(24):14210-3.

46. Dong Z, Yu J, Li H, Huang W, Xu L, Zhao Y, et al. Transcriptional and epigenetic adaptation of maize chromosomes in oat-maize addition lines. Nucleic Acids Res. 2018;46(10):5012-28.

47. Badaeva ED, Friebe B, Gill BS. Genome differentiation in Aegilops. 2. Physical mapping of $5 \mathrm{~S}$ and 18S-26S ribosomal RNA gene families in diploid species. Genome. 1996;39(6):1150-8.

48. Peng YY, Wei YM, Baum BR, Zheng YL. Molecular diversity of the $5 \mathrm{~S}$ rRNA gene and genomic relationships in the genus Avena (Poaceae: Aveneae). Genome. 2008;51(2):137-54.

49. Linares C, Ferrer E, Fominaya A. Discrimination of the closely related A and D genomes of the hexaploid oat Avena sativa L. Proc Natl Acad Sci U S A. 1998:95(21):12450-5.

50. Solano R, Hueros G, Fominaya A, Ferrer E. Organization of repeated sequences in species of the genus Avena. Theor Appl Genet. 1992;83(5): 602-7.

51. Morikawa T. Identification of the 21 monosomic lines in Avena byzantina C. Koch cv. 'Kanota'. Theor Appl Genet. 1985;70(3):271-8.

52. Bekele WA, Wight CP, Chao S, Howarth CJ, Tinker NA. Haplotype-based genotyping-by-sequencing in oat genome research. Plant Biotechnol J. 2018;16(8):1452-63.

53. Xiang FN, Xia GM, Chen HM. Asymmetric somatic hybridization between wheat (Triticum aestivum) and Avena sativa L. Sci China Ser C. 2003;46(3): 243-52.

54. An H, Hu M, Li P, Geng G, Zhang Q, Zhang S. Chromosomal behavior during meiosis in the progeny of Triticum timopheevii $\mathrm{x}$ hexaploid wild oat. PLoS One. 2015;10(5):e0126398

55. Benson G. Tandem repeats finder: a program to analyze DNA sequences. Nucleic Acids Research. 1999;27(2):573-80.

56. Han FP, Lamb JC, Birchler JA. High frequency of centromere inactivation resulting in stable dicentric chromosomes of maize. Proc Natl Acad Sci USA. 2006;103(9):3238-43

57. Li G, Wang H, Lang T, Li J, La S, Yang E, et al. New molecular markers and cytogenetic probes enable chromosome identification of wheat-Thinopyrum intermedium introgression lines for improving protein and gluten contents. Planta. 2016;244(4):865-76.

58. Fu S, Chen L, Wang Y, Li M, Yang Z, Qiu L, et al. Oligonucleotide probes for ND-FISH analysis to identify rye and wheat chromosomes. Sci Rep. 2015;5: 10552.

59. Bi Y, Zhao Q, Yan W, Li M, Liu Y, Cheng C, et al. Flexible chromosome painting based on multiplex PCR of oligonucleotides and its application for comparative chromosome analyses in Cucumis. Plant J. 2020;102(1):178-86.

\section{Publisher's Note}

Springer Nature remains neutral with regard to jurisdictional claims in published maps and institutional affiliations.

Ready to submit your research? Choose BMC and benefit from:

- fast, convenient online submission

- thorough peer review by experienced researchers in your field

- rapid publication on acceptance

- support for research data, including large and complex data types

- gold Open Access which fosters wider collaboration and increased citations

- maximum visibility for your research: over $100 \mathrm{M}$ website views per year

At BMC, research is always in progress.

Learn more biomedcentral.com/submissions 